\title{
Napovedovanje nogometnega zmagovalca z rekurentno nevronsko mrežo LSTM
}

\author{
Nejc Planer \\ Fakulteta za elektrotehniko, računalništvo in \\ informatiko \\ Koroška cesta 46, 2000 Maribor \\ nejc.planer@student.um.si
}

\author{
Mladen Borovič \\ Fakulteta za elektrotehniko, računalništvo in \\ informatiko \\ Koroška cesta 46, 2000 Maribor \\ mladen.borovic@um.si
}

\section{POVZETEK}

Prispevek predstavlja napovedovanje nogometnega zmagovalca in nekaterih drugih statistik z rekurentno nevronsko mrežo, ki uporablja celico LSTM. Opisano je tudi kje lahko pridobimo podatke za posamezne lige in tekmovanja, kako te podatke potem preoblikujemo in njihov končen izgled. Podamo tudi uporabljeno nevronsko mrežo, ter rezultate. To so ali pade več kot 1,5 gola na tekmo, ali pade več kot 2,5 gola na tekmo in ali obe ekipi zadeneta. Na koncu podamo še nekaj idej za možne izboljšave uspešnosti napovedovanja.

\section{Kjučne besede}

napovedovanje, rekurentne nevornske mreže, celica LSTM, nogomet, umetna inteligenca

\section{UVOD}

Stave so velik del športa in pritegnejo veliko ljudi, saj so privlačne zaradi možnega hitrega zaslužka. Problem je, da je šport lahko zelo nepredvidljiv in je težko ugotoviti končen izid. Zato si pri stavljanju velikokrat pomagamo s statistiko prejšnjih tekem, oziroma prejšnjih let. To naredi nevronske mreže zelo zanimive, saj lahko pošljemo to statistiko kot vhod v mrežo in potem ta napove rezultate za naprej.

Namen dela je ugotoviti, ali lahko z nogometno statistiko in nevronskimi mrežami uspešno napovemo, kaj se bo zgodilo $\mathrm{v}$ prihodnjih tekmah. Za to je potrebno pridobljene podatke ustrezno preoblikovati in dodati nove, da si izboljšamo natančnost. Tudi oblika mreže je pomembna, saj vse ne dosegajo iste natančnosti.

Avtor Korpič je v diplomskem delu [13] uporabil različne algoritme strojnega učenja za napovedovanje zmagovalca nogometne tekme. Uspešnost napovedovanja je bila med 30 in 50 odstotki.

Tudi v raziskovalnem delu [9] so uporabili različne algoritme strojnega učenja za napovedovanje nizozemske nogometne lige. Najboljše rezultati so bili v povprečju okoli 60 odstotkov.

Microsoft ima svoj sistem za napovedovanje športnih rezultatov. Leta 2014 so napovedali vse tekme izločevalnega dela svetovnega prvenstva pravilno [11]. Njihov matematični model vzame v račun več faktorjev, od števila zmag, porazov in neodločenih izidov vse do tipa podlage na igrišču in vremenskih razmer [10].

Za napovedovanje bomo uporabili rekurentne nevronske mreže, ki še na tem področju niso veliko uporabljene, in sicer da vidimo ali lahko z njimi dosežemo boljše rezultate kot z ostalimi metodami umetne inteligence.

V naslednjem poglavju opišemo pridobivanje podatkov, ki jih potem tudi podrobneje razložimo in povemo njihovo strukturo. Sledi njihova preobdelava preden jih pošljemo v nevronsko mrežo. Zatem v tretjem poglavju opišemo arhitekturo nevronske mreže, ki jo uporabljamo. V četrtem poglavju so predstavljeni rezultati. V petem zaključnem poglavju pa podamo smernice za nadaljnje delo.

\section{PODATKI}

\subsection{Pridobivanje podatkov}

Nekatere zgodovinske podatke o nogometu smo našli na spletu, druge pa smo si morali zgenerirati sami. Za največje svetovne nogometne lige že obstajajo datoteke CSV za sezone od začetka 90. let naprej [4]. Najdemo lahko tudi datoteke CSV za vsa svetovna prvenstva [3].

Za slovensko nogometno ligo smo si morali napisati svoj program [6]. Ta je iz podatkov iz wikipedije [7] in uradne strani Prve slovenske nogometne lige [5] razbral prave informacije in jih shranil $\mathrm{v}$ datoteko CSV. Največja težava pri tem je bila, da so se imena klubov skozi leta veliko spreminjala in je bilo potrebno kar nekaj ročnega dela, da smo povezali skupaj prava imena klubov.

Prav tako smo morali napisati program za pridobivanje podatkov tekmovanja Copa America [1]. Ta je iz podatkov iz wikipedije [2] ustvaril datoteko CSV, vendar smo morali podatke za določene tekme vnesti sami, saj ima wikipedija nekonsistentno kodo.

\subsection{Opis podatkov}

Določene datoteke CSV so imele veliko število podatkov, zato smo vzeli le ključne za nas. Prvi podatek je kvote iz 
stavnice Bet365. Pogledali smo 3 kvote, in sicer za zmago domače ekipe, za neodločen izid in za zmago tuje ekipe. Tega podatka za slovensko ligo žal ni bilo mogoče najti. Naslednji podatek je bil ime ekipe. Sledilo je število zadetkov obeh ekip in pa kdo je zmagal, torej domača ekipa, neodločen izid ali pa tuja ekipa.

\subsection{Preoblikovanje podatkov}

Za vsako tekmo smo v upoštev vzeli vse prejšnje tekme te sezone. Tako smo si najprej izračunali zadete in prejete gole do trenutne tekme $\mathrm{v}$ sezoni. Potem je sledil izračun števila točk obeh ekip pred tekmo. Shranili smo si tudi število zmag, remijev in porazov obeh ekip pred trenutno tekmo. Za zadnjih 5 tekem obeh ekip smo beležili tudi formo. Če je ekipa zmagala je bil rezultat $\mathrm{v}$ podatkih označen $\mathrm{z} \mathrm{W}$, remi z D in poraz z L. Posebej smo z M označili tudi, če še tekma ni bila odigrana, torej v prvih petih krogih. Iz teh podatkov smo ugotovili tudi ali ima ekipa zaporedni niz zmag ali porazov. Pogledali smo za nize treh ali petih tekem. Naslednji podatek je bil, kateri zaporedni teden sezone je. Izračunali smo tudi razliko v golih in točkah med obema ekipama. Zabeležili smo tudi razliko med končnima položajema ekip v prejšnji sezoni. Če je katera izmed ekip bila prejšnjo sezono v nižji ligi, se ji je dodelila pozicija 30 , da je se je videla razlika od ekip, ki so igrale v tej ligi. Kratek pregled podatkov lahko vidimo tudi v Tabeli 1 . Preden so se podatki poslali v mrežo, se je za vse tekstovne podatke naredilo t.i. one-hot kodiranje, ki je vsak tekst enolično določilo.

\section{ARHITEKTURA NEVRONSKE MREžE}

Rekurentna nevronska mreža za razliko od navadnih, kot vhod ne dobi le vhodnega vektorja, temveč tudi stanje iz preteklosti. To je smiselno, kadar se neka informacija lahko skriva v samem zaporedju dogodkov. Najpogosteje uporabljen nevron pri teh tipih mreže pa je celica LSTM (Long short-term memory).

Uporabljena rekurentna nevronska mreža ima 4 plasti. Prve tri plasti imajo po 32 nevronov, zadnja pa 2 nevrona, saj imamo tudi toliko izhodov. Implementirali smo jo v programskem jeziku Python [8] in uporabili njegovo knjižnico za umetno inteligenco Keras [12]. V kodi samo ustvarimo sekvenčni model in dodamo število željenih plasti ter jim določimo število nevronov. Na koncu vsake plasti smo dodali še aktivacijsko funkcijo sigmoid, ki nam še dodatno normalizira vrednosti. Za prvimi tremi plastmi lahko vidimo tudi funkcjio izpuščanja (ang. Dropout function), ki poskrbi da se določen delež naučenega pozabi in tako ne prihaja do prekomernega prileganja.

\section{REZULTATI}

Rezultate razdelimo na dva dela. Najprej podamo napovedovanja tekem ligaških sezon, nato pa nogometnih turnirjev. Model naučimo vse do zadnje sezone oziroma turnirja, zadnjo pa uporabimo kot testno množico.

Za zaganjanje uporabljamo računalnik s procesorjem Intel i5-4750 3,6GHz, grafično kartico NVIDIA GeForce GTX 960 in 8 GB RAM pomnilnika.

Tabela 1: Vhodni podatki

\begin{tabular}{|c|c|}
\hline Vhodni podatek & Razlaga \\
\hline Kvote stavnice Bet365 & $\begin{array}{l}\text { trije podatki: kvota } \\
\text { za zmago domače } \\
\text { ekipe, kvota za } \\
\text { neodločen izid in } \\
\text { kvota za zmago tuje } \\
\text { ekipe }\end{array}$ \\
\hline Śtevilo zadetih golov & $\begin{array}{l}\text { Koliko golov je } \\
\text { zadela vsaka ekipa } \\
\text { do tega trenutka v } \\
\text { sezoni }\end{array}$ \\
\hline Śtevilo prejetih golov & $\begin{array}{l}\text { Koliko golov je } \\
\text { prejela vsaka ekipa } \\
\text { do tega trenutka v } \\
\text { sezoni }\end{array}$ \\
\hline Točke & $\begin{array}{l}\text { Koliko točk imata } \\
\text { obe ekipi v tem } \\
\text { trenutku sezone }\end{array}$ \\
\hline Pregled statistike tekem & $\begin{array}{l}\text { Stevilo zmag, } \\
\text { remijev in porazov } \\
\text { obeh ekip do tega } \\
\text { trenutka v sezoni }\end{array}$ \\
\hline Forma zadnjih 5 tekem & $\begin{array}{l}\text { Za vsako izmed } \\
\text { zadnjih } 5 \text { tekem ali } \\
\text { je bila zmaga }(\mathrm{W}) \text {, } \\
\text { remi }(\mathrm{D}), \text { poraz }(\mathrm{L}) \\
\text { ali pa še ni bila } \\
\text { odigrana }(\mathrm{M})\end{array}$ \\
\hline Igralen teden & $\begin{array}{l}\text { Kateri zaporedni } \\
\text { teden sezone je }\end{array}$ \\
\hline Niz zmag & $\begin{array}{l}\text { Ali je ekipa zadnje } 3 \\
\text { ali } 5 \text { tekem zmagala }\end{array}$ \\
\hline Niz porazov & $\begin{array}{l}\text { Ali je ekipa zadnje } 3 \\
\text { ali } 5 \text { tekem izgubila }\end{array}$ \\
\hline Razlika v golih & $\begin{array}{l}\text { Stevilo zadetih golov } \\
\text { - število prejetiih } \\
\text { golov }\end{array}$ \\
\hline Razlika v točkah & $\begin{array}{l}\text { Točke domače ekipe } \\
\text { - točke tuje ekipe }\end{array}$ \\
\hline $\begin{array}{l}\text { Razlika v lanskih } \\
\text { položajih na lestivic }\end{array}$ & $\begin{array}{l}\text { Lanski končni } \\
\text { položaj domače } \\
\text { ekipe - lanski končni } \\
\text { položaj tuje ekipe } \\
\text { (če katera od ekip v } \\
\text { prejšnji sezoni ni } \\
\text { igrala v tej ligi, se ji } \\
\text { dodeli pozicija } 30, \\
\text { tako da je razlika od } \\
\text { ostalih) }\end{array}$ \\
\hline Ekipa & Ime ekipe \\
\hline Rezultat & $\begin{array}{l}\text { H - zmaga domače } \\
\text { ekipe, NH - } \\
\text { neodločeno ali poraz } \\
\text { domače ekipe }\end{array}$ \\
\hline
\end{tabular}

\subsection{Napovedovanje tekem ligaške sezone}


Tabela 2: Uspešnost napovedovanja zmagovalca tekme glede na različno število plasti

\begin{tabular}{|c|c|c|}
\hline & \multicolumn{2}{|c|}{ Mrě̌a } \\
\hline Liga & $\mathbf{2}$ plasti & $\mathbf{4}$ plasti \\
\hline Italijanska liga & $70,97 \%$ & $\mathbf{7 1 , 8 4 \%}$ \\
\hline Angleška liga & $70,53 \%$ & $\mathbf{7 0 , 7 9 \%}$ \\
\hline Nemška liga & $67,65 \%$ & $\mathbf{6 9 , 9 3 \%}$ \\
\hline Španska liga & $65,26 \%$ & $\mathbf{6 6 , 0 5 \%}$ \\
\hline Francoska liga & $\mathbf{6 5 , 5 3 \%}$ & $63,68 \%$ \\
\hline Slovenska liga & $61,11 \%$ & $\mathbf{6 1 , 6 7 \%}$ \\
\hline
\end{tabular}

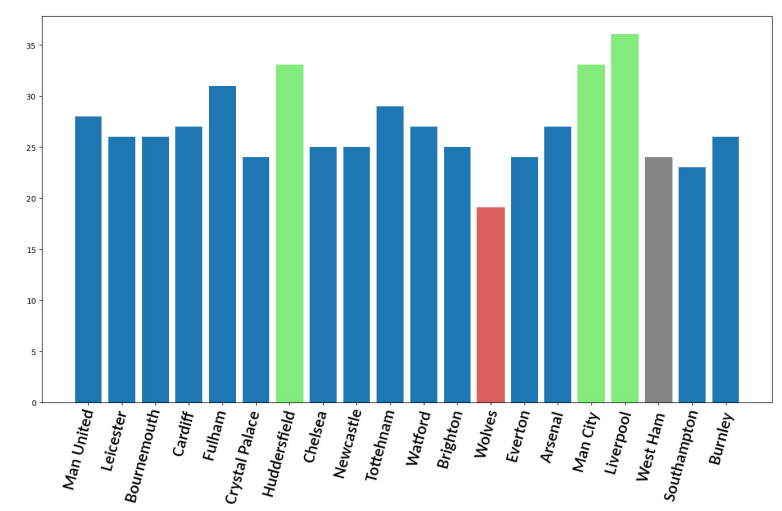

Slika 1: Uspešnost napovedovanja za posamezno ekipo znotraj zadnje sezone angleške lige

Lige se načeloma med seboj razlikujejo le po številu ekip, edino v slovenski ligi je drugačen sistem igranja, saj imajo ekipe med seboj štiri tekme namesto dveh.

V Tabeli 2 vidimo primerjavo napovedovanja zmagovalca med mrežo z dvema plastema in štirimi plastmi nevronov LSTM. Vidimo, da se nevronska mreža z manj plastmi slabše odnese, ampak je pa načeloma manj častovno zahtevna in pride običajno do rezultata $\mathrm{v}$ polovičnem času v primerjavi z mrežo s štirimi plastmi. Ker za slovensko ligo nimamo podatkov za kvote na stavnicah in vidimo slabšo napovedljivost, lahko sklepamo, da so kvote pomemben faktor pri učenju nevronske mreže. Ostale lige pa imajo iste podatke na vhodu, kar pomeni, da sta italijanska in angleška liga manj naključni, kot pa francoska in španska, nemška pa je nekje vmes.

Če podrobneje pogledamo rezultate, lahko vidimo, da prihaja tudi do razlik med ekipami, saj se rezultate določene ekipe lažje napove kot druge, kar lahko za angleško ligo vidimo na Sliki 1 . Najbolje se napoveduje Liverpool (36 od 38 pravilnih), Manchester City (33 od 38 pravilnih) in pa Huddersfield (33 od 38 pravilnih), ki so označeni z zeleno. Če pogledamo lestvico, so to prva, druga in pa zadnja ekipa v ligi, torej ji večje probleme delajo ekipe iz sredine lestvice, kar pa je tudi logično, saj so te majn konsistentne. Najslabše napovedljiv je Wolves, ki je označen z rdečo, in sicer le 19 od 38 tekem pravilnih. Če pogledamo ekipo iz sredine lestvice (10 mesto), West Ham, ki je označen s sivo in je pravilno napovedanih 24 od 38 tekem.
Tabela 3: Uspešnost napovedovanja, ali pade več kot 1,5 gola na tekmo

\begin{tabular}{|c|c|}
\hline Liga & Uspešnost napovedi (v odstotkih) \\
\hline Italijanska liga & $74,74 \%$ \\
\hline Angleška liga & $79,74 \%$ \\
\hline Nemška liga & $84,64 \%$ \\
\hline Španska liga & $73,95 \%$ \\
\hline Francoska liga & $71,23 \%$ \\
\hline Slovenska liga & $81,67 \%$ \\
\hline
\end{tabular}

Tabela 4: Uspešnost napovedovanja, ali pade več kot 2,5 gola na tekmo

\begin{tabular}{|c|c|}
\hline Liga & Uspešnost napovedi (v odstotkih) \\
\hline Italijanska liga & $53,68 \%$ \\
\hline Angleška liga & $57,63 \%$ \\
\hline Nemška liga & $63,73 \%$ \\
\hline Spanska liga & $55,00 \%$ \\
\hline Francoska liga & $60,00 \%$ \\
\hline Slovenska liga & $62,78 \%$ \\
\hline
\end{tabular}

V Tabeli 3 je uspešnost napovedovanja, ali na tekmo pade več kot 1,5 gola. Napovedljivost tega izgleda precej boljša kot pa napovedljivost zmagovalca. Ce podrobneje preučimo napovedovanje, lahko vidimo, da mreža $\mathrm{v}$ trenutku pride do lokalnega minimuma iz katerega se kasneje ne spremeni na bolje. Ce pa pogledamo dejanske napovedi, pa lahko vidimo, da $\mathrm{v}$ večini primerov pride do spoznanja, da skoraj vedno pade več kot 1,5 gola na tekmo. Torej so te natančnosti bolj ali manj enake dejanskemu odstotkovnemu številu tekem, ko pade več kot 1,5 gola na tekmo.

$\mathrm{V}$ Tabeli 4 je uspešnost napovedovanja, ali na tekmo pade več kot 2,5 gola. Kot lahko vidimo je napovedljivost slaba. $\mathrm{Ni}$ enak problem kot pri več kot 1,5 gola na tekmo, saj tu ne pride do rešitve, da bi naj to bilo vedno res, ampak iz teh vhodnih podatkov ne moremo razbrati nekega vzorca, kdaj bi temu bilo tako.

$\mathrm{V}$ Tabeli 5 je uspešnost napovedovanja, ali obe ekipi na tekmi zadeneta vsaj en gol. Kot vidimo so rezultati podobno slabi kot pri napovedovanju, ali pade več kot 2,5 gola na tekmo, torej je uspešnost napovedovanja kar slaba.

\subsection{Napovedovanje tekem nogometnih turnir- jev}

Malo drugačen sistem igranja pa se pojavlja na večjih nogometnih turnirjih kot je recimo svetovno prvenstvo, saj se

Tabela 5: Uspešnost napovedovanja, ali obe ekipi na tekmi zadeneta vsaj en gol

\begin{tabular}{|c|c|}
\hline Liga & Uspešnost napovedi (v odstotkih) \\
\hline Italijanska liga & $62,37 \%$ \\
\hline Angleška liga & $54,74 \%$ \\
\hline Nemška liga & $59,48 \%$ \\
\hline Śpanska liga & $57,89 \%$ \\
\hline Francoska liga & $55,79 \%$ \\
\hline Slovenska liga & $66,11 \%$ \\
\hline
\end{tabular}


Tabela 6: Uspešnost napovedovanja zmagovalca

\begin{tabular}{|c|c|}
\hline tekme \\
\hline Tekmovanje & $\begin{array}{l}\text { Natančnost napovedovanja } \\
\text { zmagovalca }\end{array}$ \\
\hline Copa America & $65,62 \%$ \\
\hline Svetovno prvenstvo & $65,28 \%$ \\
\hline
\end{tabular}

Tabela 7: Uspešnost napovedovanja skupinskega in izločevalnega dela tekmovanja

\begin{tabular}{|c|l|l|}
\hline Tekmovanje & $\begin{array}{l}\text { Uspešnost } \\
\text { napovedi } \\
\text { skupinskega } \\
\text { dela }\end{array}$ & $\begin{array}{l}\text { Uspešnost } \\
\text { napovedi } \\
\text { izločevalnega } \\
\text { dela }\end{array}$ \\
\hline Copa America & $58,3 \%$ & $87,5 \%$ \\
\hline Svetovno prvenstvo & $58,3 \%$ & $72,9 \%$ \\
\hline
\end{tabular}

igranje deli na dva dela, to sta skupinski in izločevalni del.

V Tabeli 6 vidimo uspešnost napovedovanja zmagovalca tekme na svetovnem prvenstvu in pa turnirju Copa America. Obe tekmovanji sta približno isto napovedljivi. Imata tudi podoben trend, in sicer da ima mreža večje probleme z napovedovanjem skupinskega dela turnirja (pod 60 odstotkov), medtem ko izločilni del predvideva dobro, od 70 do 90 odstotkov natančno, kar lahko vidimo v Tabeli 7 .

\section{ZAKLJUčEK}

Prispevek predstavlja napovedovanje določenih statistik nogometne tekme z rekurentno nevronsko mrežo LSTM. Ta se na preteklih rezultatih nauči določenih vzorcev in poskuša napovedati prihodnje tekme. Za to smo morali zbrati dovolj veliko podatkov in jih ustrezno predelati. Pomembna je bila tudi struktura nevronske mreže, torej število skritih plasti in število nevronov $\mathrm{v}$ teh plasteh.

Rekurentna nevronska mreža se uporabi na primeru napovedovanja zmagovalca nogometne tekme, ali pade več kot 1,5 ali 2,5 gola na tekmo in ali obe ekipi zadeneta. Uporabljene so angleška, francoska, italijanska, nemška, španska in slovenska liga ter tekmovanji Copa America in svetovno prvenstvo. Napovedljivost zmagovalca ligaških tekem je od 61 do 72 odstotkov, zmagovalca nogometnih turnirjev pa od 65 do 66 odstotkov. Napovedljivost, ali pade več kot 1,5 gola je od 71 do 85 odstotkov, ali pade več kot 2,5 pa od 53 do 64 odstotkov, podobni rezultati so tudi pri napovedovanju, ali obe ekipi zadeneta, in sicer od 54 do 67 odstotkov.

Nadaljne delo bi zajemalo pridobivanje večjega števila podatkov. Za nogometne lige imamo podatke od začetka 90 . let naprej, kar za Slovenijo sicer predstavlja 100 odstotkov podatkov, ampak ostale lige pa segajo dalje v preteklost in bi ti podatki mogoče lahko pomagali. Še ena izboljšava bi bila drugačno preoblikovanje podatkov, oziroma uporaba drugih podatkov nogometne statistike (npr. število kotov ali število kartonov). Zanimivo bi bilo tudi preizkusiti drugačno arhitekturo nevronske mreže $\mathrm{v}$ smislu različnih plasti rekurentne nevronske mreže ali pa kombinacijo različnih tipov nevronskih mrež.

\section{LITERATURA}

[1] Copa america web scraper. https: //github.com/planeer/CopaAmericaWebScraper, 19. 6. 2019.

[2] Copa américa. https: //en.wikipedia.org/wiki/Copa_Am\%C3\%A9rica, 19. 6. 2019.

[3] Fifa world cup. https://www .kaggle.com/abecklas/fifa-world-cup, 19. 6. 2019.

[4] Football betting | football results | football bets | football odds. http://www.football-data.co.uk/, 19. 6. 2019.

[5] Plts - prva liga telekoma slovenije. https://www.prvaliga.si/prvaliga/default.asp, 19. 6. 2019.

[6] Prva liga web scraper. https://github.com/planeer/PrvaLigaWebScraper, 19. 6. 2019.

[7] Slovenian prvaliga. https:

//en.wikipedia.org/wiki/Slovenian_PrvaLiga, 19. 6. 2019.

[8] Python. https://www.python.org/, 2. 7. 2019.

[9] Dutch football prediction using machine learning classifiers. https://pdfs. semanticscholar.org/ b347/e38d5c61a139115884fbff352221c4f7bfe1.pdf, 22. 8. 2019.

[10] Microsoft has perfectly predicted this stage of the world cup and it thinks brazil is finished.

https://qz.com/231583/

microsoft-world-cup-predictions-brazil-germany/, 22. 8. 2019.

[11] With germany's win microsoft perfectly predicted the world cup's knockout round. https://qz.com/233830/ world-cup-germany-argentina-predictions-microsoft/, 22. 8. 2019.

[12] Keras. https://keras.io/, 29. 6. 2019.

[13] Žan Korpar. Predikcija športnih rezultatov z uporabo strojnega učenja. Fakulteta za elektrotehniko, računalništvo in informatiko Univerze v Mariboru, Maribor, 2018. 